\title{
THE FACTORIAL STRUCTURE OF JOB-RELATED AFFECTIVE WELL-BEING: POLISH ADAPTATION OF THE WARR'S MEASURE
}

\author{
EMILIA MIELNICZUK and MARIOLA ŁAGUNA
}

The John Paul II Catholic University of Lublin, Lublin, Poland

Institute of Psychology, Department of General Psychology

\begin{abstract}
Objectives: The first aim of the study reported in this article was to test the factorial structure of job-related affect in a Polish sample. The second aim was to develop the Polish adaptation of the Warr's job-related affective well-being measure published in 1990, which is designed to assess 4 types of affect at work: anxiety, comfort, depression, enthusiasm. Material and Methods: A longitudinal study design with 2 measurement times was used for verifying the psychometric properties of the Polish version of the measure. The final sample consisted of 254 Polish employees from different professions. Participants were asked to fill in a set of questionnaires consisting of measures capturing job-related affective well-being, mood, and turnover intention. Results: The first step of analysis was to test the theoretically-based structure of the job-related affective well-being measure in a Polish sample. The confirmatory factor analysis revealed that a 4-factor model best describes the structure of the measure in comparison to 5 alternative models. Next, reliability of this measure was assessed. All scales achieved good internal consistency and acceptable test-retest reliability after 2 weeks. Finally, the convergent and discriminant validity as well as the criterion and predictive validity of all job-related affective well-being scales was confirmed, based on correlations between job-related affect and mood as well as turnover intention. Conclusions: The results suggest that the Polish adaptation of Warr's job-related affective well-being measure can be used by scientists as well as by practitioners who aim at assessing 4 types of affective well-being at a work context. Int J Occup Med Environ Health 2018;31(4):429-443
\end{abstract}

Key words:

Mood, Employees, Turnover intention, Circumplex model of affect, Job-related affective well-being, Longitudinal research

\section{INTRODUCTION}

For a long time, there was a dominant opinion that emotions and rational thinking and acting are mutually exclusive. That is why researchers did not perceive emotions as important factors that may be related to job performance [1]. Nowadays, however, the interest in affect in the organizational context is increasing, since there is growing evidence that emotional reactions are connected with rational decision making [2], as well as with health [3], and different work outcomes [4]. For these reasons the interest in tools dedicated to the assessment of affect at work is rising, especially that there are only a few measures capturing affect in a work context available [5,6]. A broadly used method $[4,7,8]$ is the job-related affective well-being measure developed by Warr [9]. The aim of this article is to analyze the factorial structure and psychometric properties of this tool using longitudinal data from Polish employees. We present the Polish adaptation of Warr's

The adaptation has been prepared with the permission of Peter Warr, the author of the original measure.

Funding: This research was financed by the Polish National Science Centre (grant No. DEC-2013/10/M/HS6/00475 "Multilevel analysis of entrepreneurial success," principal investigator: Mariola Laguna, Ph.D.).

Received: January 8, 2017. Accepted: July 24, 2017.

Corresponding author: Emilia Mielniczuk, The John Paul II Catholic University of Lublin, Institute of Psychology, Al. Racławickie 14, 20-950 Lublin, Poland (e-mail: mielniczuk.e@gmail.com). 
measure of job-related affective well-being dedicated to capturing 4 dimensions of affect at work.

\section{Affect and its role in a work context}

Dictionary definitions of "emotions," "affect," and "feelings" overlap and there is no clear distinction between them [e.g., 10]. Similarly, researchers propose diverse definitions distinguishing (or not) these concepts [11]. In this paper we follow the conceptualization of affect proposed by Fredrickson [12]. According to her theory, when something important happens, it triggers numerous affective responses. Emotions are relatively short in duration, and they may be conscious or unconscious. Affect is a more general concept then emotions and moods, and it refers to consciously accessible feelings. Unlike emotions, which always have an object, affect may be objectless [12]. Following this conceptualization, we treat affect as consciously accessible feelings, evident in moods and emotions.

Research findings increasingly show that affect has an important influence on individuals' behavior, including a work context $[3,13,14]$. According to the broad theory, positive emotions predict positive outcomes by broadening the way individuals process information and increasing the number of goals they want to pursuit [15]. The theory holds that such a broadening process, which is triggered by positive emotions, helps to build more durable personal resources, including physical, social, intellectual, and psychological ones [12]. In the occupational context, it has been revealed that positive emotions influence a variety of performance-relevant outcomes such as judgments, creativity, helping behavior, and risk taking [16], help to reduce occupational stress [14] and are connected with work engagement [4,17]. Negative emotions also play an important role in an organizational context. They are strongly connected with occupational stress and may lead to psychological breakdown [3] and burnout [18]. What is more, they relate to workplace incivility [19] and various counterproductive work behaviors, such as mobbing, antisocial behavior, aggression or withdrawal [20]. There is also evidence that positive affect towards personal work-related goals is positively related whereas negative affect is negatively related to the goal achievement [21]. All those research findings clearly demonstrate that it is important to take affect into account when investigating activity at work.

\section{Conceptualizations of affective dimensions}

The considerable interest in subjective well-being has led to several conceptualizations of affect and its dimensions. Researchers have proposed diverse theories concerning the structure of affect and suggestions about how affect should be captured. For instant Diener et al. [22] claim that positive and negative affect should be treated as 2 poles of 1 dimension since these 2 states are unlikely to be experienced at the same time. Their study has revealed that the more frequently positive affect occurs, the less frequently negative affect is experienced.

This one-dimensional approach is, however, criticized by other researchers who claim that positive and negative affect are 2 independent constructs [23]. Warr et al. [24] claim that the correlation between numbers of desirable and undesirable episodes of life events as well as experienced feelings is not high enough to make a prediction about duration of negative affect based on duration of positive affect. According to Argyle and Martin [25], positive and negative affect have different causes, and Davidson [26] has revealed that positive affect is connected with left frontal activation of the brain, while negative emotions are related to right frontal activation.

Nowadays, a more popular notion is that diverse affective states are related to each other in a highly systematic way [27]. They are often categorized along 2 dimensions: pleasantness and emotional activation [28]. Pleasantness divides emotions into positive and negative ones whereas activation refers to high or low arousal. These are basic dimensions of the widely acknowledged and empirically supported circumplex model of affect [27,29]. This cir- 


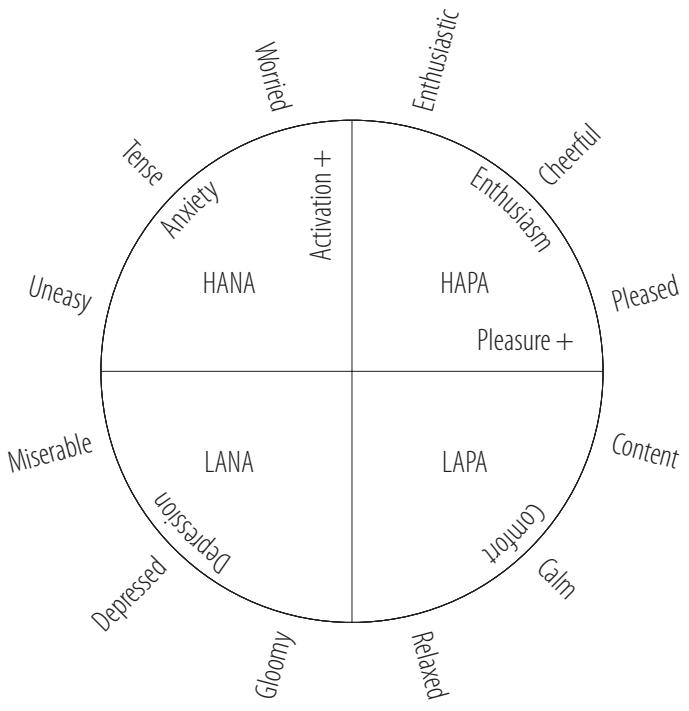

Adapted and published with permission from John Wiley \& Sons Ltd from Warr P. The measurement of well-being and other aspects of mental health. J Occup Psychol. 1990;63(3):193-210.

(C) 1990 The British Psychological Society.

HANA - activated negative affect; HAPA - activated positive affect; LANA - low activation negative affect; LAPA - low-activation positive affect.

Fig. 1. Four-factor model of Warr's job-related affective well-being measure [9]

cumplex model was applied by Warr [9] to the work context. In his conception job-related affective well-being is defined by 2 principal dimensions of pleasure (horizontal) and arousal (vertical) (Figure 1), however, according to Warr [9], arousal by itself is not a reflection of affect. This model allow to describe both the content and the intensity of job-related affective states and to represent affective well-being along 3 key axes: displeased-pleased, anxietycontentment (called also anxiety-comfort), and depression-enthusiasm. Thanks to this it is possible to describe not only valence, i.e., positive and negative affect but also to distinguish diverse content of affective experiences at work. In consequence each specific job-related affect can be understood as a linear combination of both valence and arousal, and arise from "cognitive interpretations of core neural sensations that are the products of 2 independent neurophysiological systems" [29, p. 715].

\section{Warr's job-related affective well-being measure}

Based on this model, Warr [9] created the measure of job-related affective well-being intended to capture 4 affective dimensions: anxiety, comfort (labelled earlier contentment), depression, and enthusiasm. These scales capture the endpoints of 2 circumplex model axes: anxiety-comfort and depression-enthusiasm, while a third axis: displeased-pleased is considered to depict job satisfaction which is measured by other scales [9]. The Warr job-related affective well-being measure is a short instrument built of 12 items, each of them being a single adjective [9]. The respondents evaluate on a six-point scale $(1-$ never, 6 - all of time) how frequently their work made them feel certain feelings during the past few weeks. There are 6 positive (calm, contented, relaxed, cheerful, enthusiastic, optimistic) and 6 negative (tense, uneasy, worried, depressed, gloomy, miserable) feelings. The score on each of 4 proposed scales of the instrument is a mean or a sum of 3 items. The time allotted for filling in the measure is very short and does not exceed $5 \mathrm{~min}$, which makes the instrument very useful in research with many measures and in on-line questionnaires. As this measure has clear theoretical underpinnings it has become very popular in research in work and organizational psychology $[4,7,8]$.

There are also other measures of affect available. One of the most popular, the Positive and Negative Affect Schedule (PANAS) [6], captures positive and negative general, context-free affect. The University of Wales Institute of Science and Technology (UWIST) Mood Adjective Checklist (UMACL) [30], which consists of 3 dimensions - energetic arousal, tense arousal and hedonic tone - is designed to measure rather short-lived feeling states like mood. However, none of these scales is designed specifically for measuring affect in a work context. They also do not cover the whole spectrum of affect depicted by the circumplex model (e.g., PANAS does not cover low activation affect). The measure which captures affect in a work context is the Job-related Affective Well-being Scale (JAWS) [5]. It also 
refers to Warr's model of affective well-being at work [5] and assess people's emotional reactions to their job in the past month which are categorized along 2 dimension: pleasurableness (positive and negative affect) and arousal (high and low intensity). This hypothesized 4-factor structure was confirmed in a Polish sample of police officers [31]. As this method is longer (30 items in a full and 20 items in a short version) than the Warr [9] jobrelated affective well-being measure, it is less popular in research. What is more, despite the fact that the original version has good reliability [5], there are same psychometric problems in various non-English versions [31]. The advantage of the Warr measure is also that it allows to capture diverse content of 4 affective experiences at work which have clear theoretical foundations in the circumplex model of affect $[27,29]$. Having already the Polish adaptation of the JAWS scale, we have developed the Polish adaptation of Warr's instrument. As a Polish name of the Warr measure we propose to use Kwestionariusz Afektu w Pracy (KAP). This name allows us to distinguish the measure form JAWS, which is called in Polish Skala Dobrostanu Emocjonalnego w Pracy [32].

The popularity of the Warr measure raises the issue of how many and what dimensions should be used for describing subjective-well-being in the best way. A few alternative models with the different number of factors that may be captured by Warr's instrument were tested. In previous analyses of this measure, few alternative models were tested (Table 1), using the exploratory and confirmatory factor analysis (CFA). Daniels et al. [33] revealed a 3-factor structure (positive affect, negative affect, and pleasure-displeasure factor) as the best fitting to the data. Others suggest to treat positive and negative affect as 2 main dimensions of well-being [34]. Another factor model with 2 dimensions (anxiety-comfort and depression-enthusiasm) proposed by Warr [9] has also received support in several studies $[9,33,35,36]$. Other studies have revealed only 1 common latent factor [8]. Two recent stud- ies $[7,37]$ using the CFA, identified the 4-factor model as the best representation of the structure of affective wellbeing in a work context.

In this study, 6 alternative factor models of job-related affective well-being were tested in a Polish sample: the 4-factor model (anxiety, comfort, depression, enthusiasm), based on Warr's theory, a 2-factor model (dimensions anxiety-comfort, depression-enthusiasm), another alternative 2-factor model (positive affect, negative affect), a 3-factor model (positive affect, negative affect, and pleasantness-unpleasantness), and finally a 1-factor model. On the basis of the previous research [7,37] and Warr's [9] theory we hypothesize that a 4-factor solution will best fit the data.

Since its publication in 1990, the Warr measure has been used in numerous studies and translated into many languages, for instant Finnish [7], Portuguese [38], and Spanish [35]. What is more, it is widely used in studies of various occupational groups (Table 1) such as managers and professional workers, blue-collar and white-collar employees, people working in education, and police officers $[7,35-37,39]$. Development of the Polish adaptation of the measure will allow comparisons of results from Polish samples with results from other studies. Therefore in the subsequent sections we present a study attesting to the psychometric properties of the Polish adaptation of Warr's [9] job-related affective well-being measure.

\section{Associates of affective well-being}

To asses criterion and predictive validity of the Polish version of the Warr measure, we investigated correlations of its scales with 2 constructs, namely mood and turnover intention. The first one, positive and negative mood, may be captured as a context-free phenomenon, having, however, close relationships with job-related affect, as we show below. The other, turnover intention, is strictly related to a work context.

Mood may be defined as a short-term affect and it is a quick response to an environmental stimulus [40]. Ac- 


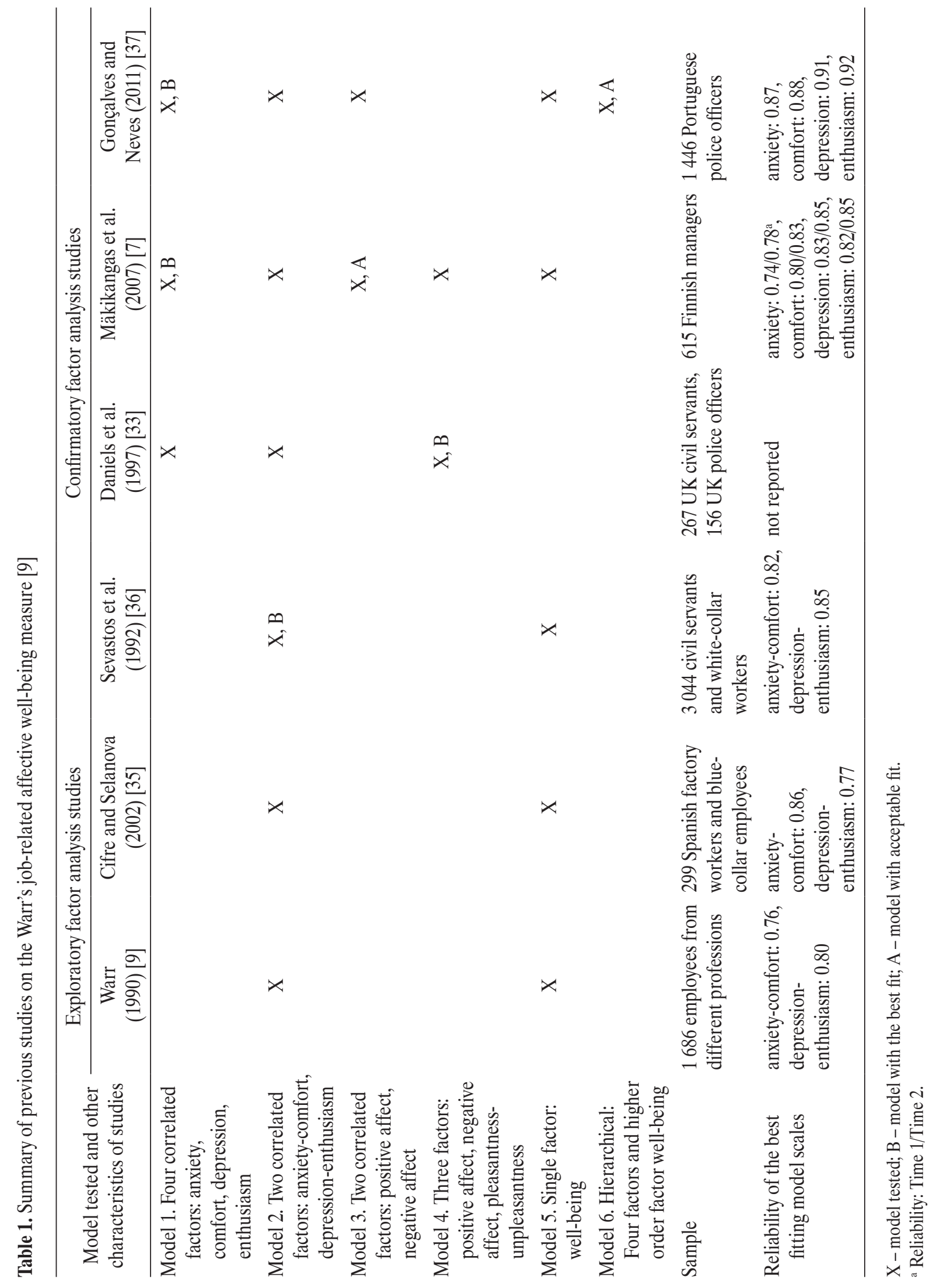


cording to the theory, work and non-work events have an impact on employees' affect both immediately and over a longer period of time [41]. This, in turn, influences work attitudes, performance and other kinds of affect-driven behavior [42]. Miner et al. [43] have revealed that mood largely determines the intensity of employees' reactions to events, depending on how good someone's mood is, he or she may experience work events differently. Rothbard and Wilk [40] have shown that start-of-workday mood of employees in call centers may predict their affect on subsequent calls and their perception of customers' affective display. Start-of-workday positive mood was positively related to employees' positive affect before calls as well as their perceptions of customers' positive affective display. In contrast, if employees started their workday with a negative mood they felt negative affect on subsequent calls and they claimed that customers also experienced a bad mood. Consistent with this, Iles and Judge [44] observed individual variations in job satisfaction across time, as their within-individual analyses showed that individuals' job satisfaction varied in synchrony with their mood.

Based on these findings, mood appears to act as an "affective prime" [43]. That is why in the current research we assume that employees' current mood is related to and may influence how they assess their affective well-being at work. More precisely, we expect that positive mood will be accompanied by enthusiasm and comfort dimensions while negative mood will be accompanied by anxiety and depression dimensions as captured by the Warr measure. Turnover is a major concern for most organizations. It is perceived as an expression of withdrawal behavior in the workplace next to the absenteeism, lateness or tardiness [20]. Turnover intention is an employee's desire to leave an organization [45]. It is a one-step before quitting from the organization, as it has been acknowledged as the best predictor of actual turnover [46,47]. The relationship between affect and turnover has been widely researched and generally the results show that positive emotions lead to positive outcomes in a work context and negative emotions bring unwanted effects $[3,4,14,18]$. More specifically, they showed that positive affect lowers turnover intention, while negative affect fosters it $[20,45,48]$. Based on the previous research we expect that there will be positive relationship between anxiety and depression and turnover intention, and negative relationship between enthusiasm and comfort and turnover intention.

\section{MATERIAL AND METHODS}

\section{Procedure and participants}

A longitudinal study with 2 measurement times at 2 week intervals was carried out. Data was collected anonymously, and participants provided their personal codes which enabled us to match their data from the first and second study waves. Involvement in the study was voluntary and there was no reward for participants. The researchers visited participants in their workplace or during their postgraduate trainings and asked them if they would be willing to complete a questionnaire.

In the first study wave (Time 1) 380 Polish employees from various professions were asked to complete the paper-and-pencil questionnaires. Two weeks later (Time 2) questionnaires were given to all the respondents who had participated in the first study wave. The response rate at time 2 was $67.11 \%(\mathrm{~N}=255)$. Most of the analyses presented in this paper are based on the data from the first study wave. Univariate analyses of variance indicated that there were no significant differences in gender, age, and main work characteristics between the participants who took part in both study waves and participants who dropped out after Time 1 (all $p>0.05$ ).

The whole sample in Time 1 comprised 133 men (35\%) and 247 women (65\%). The age of participants ranged from 18 to 64 years old, average age was 32.81 years old (standard deviation $(\mathrm{SD})=8.90)$. In the total sample $54.7 \%$ had full-time work contract, $23.2 \%$ had parttime work and $22.1 \%$ had other types of job agreement. 
Most of the employees (91.3\%) worked in the service sector, $5.5 \%$ in the construction sector and $3.2 \%$ in industry.

\section{Measures}

Job-related affect was measured by Warr's job-related affective well-being measure described in detail in the Introduction section. The instrument was translated into Polish by 4 independent translators. Based on these translations, the Polish version was elaborated, and then back-translated. The final Polish version of the items is presented in the Table 2. The scales' reliability is presented in the "Results" section.

Mood was evaluated using a 10 item scale developed by Wojciszke and Baryła [49]. Participants rated their agreement with statements describing their mood. The responses to each item were given on a five-point scale (from 1 - "I do not agree" to 5 - "I agree"). There were 5 statements covering positive mood (e.g., "I feel excellent") and 5 describing negative mood (e.g., "I am in a bad mood"). A higher score indicates a higher level of each kind of mood. Cronbach's $\alpha$ is 0.92 for negative mood and 0.91 for positive mood at Time 1 and 0.93 , and 0.92 respectively at Time 2, confirming high reliability of both scales.

Turnover intention was measured by a three-item measure [50]. An example item is "I think a lot about leaving the organization." Each statement was responded to on a 5-point scale (ranging from 1 - "strongly disagree" to 5 - "strongly agree"). A higher score indicates a higher intention to leave an organization. Cronbach's $\alpha$ is 0.90 at

Table 2. Descriptive statistics and correlations between the items of Warr's job-related affective well-being measure [9] in a sample of Polish employees $(\mathrm{N}=380)$

\begin{tabular}{|c|c|c|c|c|c|c|c|c|c|c|c|c|c|c|}
\hline \multirow{2}{*}{$\begin{array}{l}\text { Original item } \\
\text { and its Polish version* }\end{array}$} & \multirow{2}{*}{ M } & \multirow{2}{*}{$\mathrm{SD}$} & \multicolumn{12}{|c|}{ Correlation** } \\
\hline & & & 1 & 2 & 3 & 4 & 5 & 6 & 7 & 8 & 9 & 10 & 11 & 12 \\
\hline 1. Relaxed / Zrelaksowany & 3.15 & 1.21 & 1 & & & & & & & & & & & \\
\hline 2. Worried / Zmartwiony & 2.55 & 1.10 & -0.38 & 1 & & & & & & & & & & \\
\hline 3. Depressed / Przygnębiony & 2.22 & 1.13 & -0.36 & 0.61 & 1 & & & & & & & & & \\
\hline 4. Calm / Spokojny & 3.75 & 1.04 & 0.66 & -0.50 & -0.48 & 1 & & & & & & & & \\
\hline 5. Content / Zadowolony & 3.78 & 1.13 & 0.68 & -0.41 & -0.49 & 0.73 & 1 & & & & & & & \\
\hline 6. Gloomy / Posępny & 2.01 & 1.08 & -0.35 & 0.56 & 0.82 & -0.48 & -0.51 & 1 & & & & & & \\
\hline $\begin{array}{l}\text { 7. Optimistic / } \\
\text { Optymistyczny }\end{array}$ & 3.81 & 1.27 & 0.62 & -0.36 & -0.43 & 0.62 & 0.74 & -0.44 & 1 & & & & & \\
\hline 8. Tense / Spięty & 2.83 & 1.10 & -0.45 & 0.62 & 0.48 & -0.48 & -0.38 & 0.45 & -0.32 & 1 & & & & \\
\hline $\begin{array}{l}\text { 9. Enthusiastic / } \\
\text { Entuzjastyczny }\end{array}$ & 3.58 & 1.29 & 0.64 & -0.31 & -0.38 & 0.55 & 0.73 & -0.42 & 0.84 & -0.29 & 1 & & & \\
\hline 10. Cheerful / Radosny & 3.77 & 1.16 & 0.61 & -0.34 & -0.42 & 0.62 & 0.75 & -0.45 & 0.79 & -0.34 & 0.84 & 1 & & \\
\hline $\begin{array}{l}\text { 11. Miserable / } \\
\text { Nieszczęśliwy }\end{array}$ & 1.79 & 1.09 & -0.33 & 0.58 & 0.74 & -0.46 & -0.50 & 0.74 & -0.46 & 0.44 & -0.41 & -0.42 & 1 & \\
\hline 12. Uneasy / Niespokojny & 2.77 & 1.12 & -0.44 & 0.71 & 0.57 & -0.53 & -0.42 & 0.53 & -0.39 & 0.79 & -0.33 & -0.39 & 0.51 & 1 \\
\hline
\end{tabular}

* Items translated and published with the permission from John Wiley \& Sons Ltd from Warr P. The measurement of well-being and other aspects of mental health. J Occup Psychol. 1990;63(3):193-210. ㅇ 1990 The British Psychological Society.

$\mathrm{M}$ - mean; SD - standard deviation.

** All correlations are statistically significant at the level of at least $\mathrm{p}<0.01$. 
Time 1 and 0.91 at Time 2, indicating high reliability of this measure.

\section{Data analysis strategy}

First, descriptive statistics and correlations between single items were analyzed. Next, to examine the factorial structure of the job-related affective well-being measure - the CFA was conducted using AMOS [51]. Finally, to assess psychometric properties of scales emerging from the best fitting CFA model, the descriptive statistics, internal consistency, temporal stability and validity of the scales were analyzed. These analyses were performed by using IBM SPSS 23 .

\section{RESULTS}

\section{Descriptive statistics and correlations between items}

The initial analysis concerning items in the Polish version of the Warr [9] measure was performed on the data from the first study wave (Time 1). The mean score of items ranged from 1.79 for item 9 to 3.78 for item 5 on a sixpoint scale showing no extremely low or high mean values (Table 2). As it can be expected, correlations between items describing positive and negative affect are negative, ranged from -0.29 to -0.5 , and the correlations between items with the same valence are positive, ranging from 0.41 to 0.84 , all being statistically significant.

\section{Comparison of alternative factor models}

To test the factorial structure of the job-related affective well-being measure in a Polish sample of employees, 6 alternative CFA models were tested. The first model (Model 1) consisted of 4 correlated latent factors of anxiety, comfort, depression and enthusiasm. The second model (Model 2) contained 2 correlated latent factors of anxiety-comfort and depression-enthusiasm. The third model (Model 3) also comprised 2 correlated latent factors labeled positive affect and negative affect. The fourth model (Model 4) consisted of the 3 factors of positive affect, negative affect, and pleasantness-unpleasantness. The fifth model (Model 5) included one latent factor. Finally, the sixth hierarchical model (Model 6) consisted of 4 latent factors (the same as in Model 1) and a higher order latent factor named well-being.

The models were estimated using maximum likelihood estimation on the data from the first study wave. Missing data, which did not exceed $1.5 \%$ in any item, was handled using regression imputation. The model fit was assessed by using the $\mathrm{Chi}^{2}$ Goodness-of-Fit Statistic, the Root Mean Square Error of Approximation (RMSEA), the Standardized Root Mean Square Residual (SRMR), the Comparative Fit Index (CFI), and the Akaike Information Criterion (AIC). An acceptable model fit was indicated by values below 0.08 for RMSEA and SRMR [52], values greater than 0.90 for the CFI [53,54] and the lower AIC index, the better is the model fit [55]. The alternative nested models were compared using the $\mathrm{Chi}^{2}$-difference test $\left(\Delta \mathrm{Chi}^{2}\right)$ and difference in $\mathrm{CFI}(\Delta \mathrm{CFI})[52,55]$. An absolute difference in CFI that is higher than $0.01(\Delta \mathrm{CFI}>0.01)$ would indicate a significant difference in model fit [56]. We have not improved any model based on modification indices.

Examination of alternative models shows that only the 4-correlated-factor model (Model 1) obtained acceptable fit in nearly all fit indices (Table 3), except for the RMSEA which slightly exceeded the criterial value of 0.08 . None of the alternative models reached the criteria of acceptable fit [52,55]. What is more, tests of differences confirm that the 4 correlated factor model fits the data significantly better than all other alternative models (for all comparisons $\mathrm{p}$ value for $\Delta \mathrm{Chi}^{2}$ exceeded 0.05 and $\Delta \mathrm{CFI}>0.01$ ). Summing up, examination of alternative models have confirmed that job-related affective well-being, as it is measured by the Warr's [9] instrument, formed 4 scales measuring enthusiasm, comfort, anxiety, and depression. We propose to use "entuzjazm," "zadowolenie," "niepokój," and "przygnębienie" as the Polish names for the subsequent scales. 


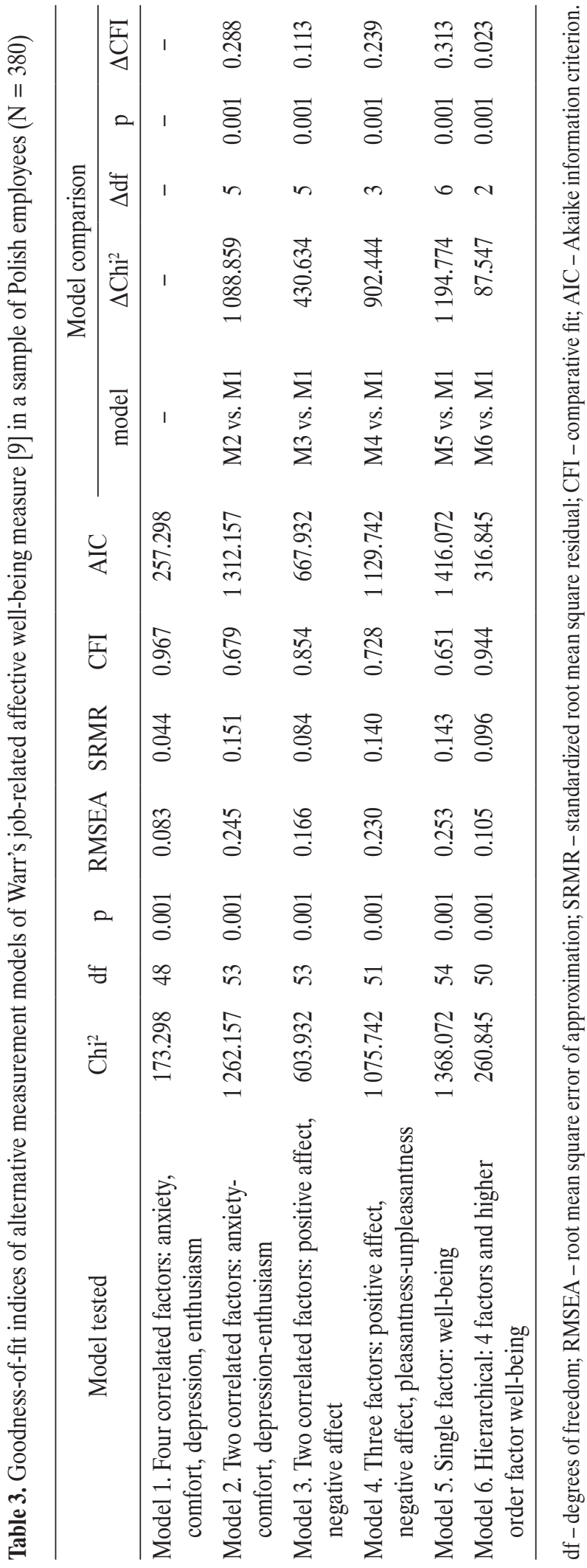

\section{Descriptive statistics and reliability of scales}

As we had confirmed the factorial structure of Warr's [9] instrument in a Polish sample, we next analyzed psychometric properties of its scales. Basic descriptive statistics and correlations between scales for both measurement times are presented in the Table 4. Correlations for scales ranged from -0.4 (between anxiety and enthusiasm) to 0.78 (between enthusiasm and comfort) at Time 1, and they ranged from -0.47 (between depression and enthusiasm) to 0.82 (between enthusiasm and comfort) at Time 2.

The reliability of the scales was assessed by evaluation of their internal consistency and test-retest stability. Cronbach $\alpha$ values (Table 4 ) show that all scales achieved good internal consistency as they ranged from 0.87 to 0.93 at Time 1 and from 0.86 to 0.93 at Time 2 . The highest reliability was for the enthusiasm scale (in both measurement times), and the lowest indicators were obtained for the scale measuring comfort at Time 1 and anxiety at Time 2 . To assess test-retest temporal stability after 2 weeks, the Pearson correlation coefficients between 2 measurement times were calculated for each scale. Test-retest correlations were 0.76 for enthusiasm, 0.72 for comfort, 0.68 for depression, and 0.65 for anxiety, all being statistically significant. These correlation coefficients demonstrate that the most stable scores were those for the enthusiasm scale. Although the anxiety scale scores were the least stable, they still indicated acceptable temporal stability, especially taking into account that the scales are very short.

\section{Convergent and discriminant validity}

Convergent validity is achieved when 3 requirements are fulfilled: all factor loadings are statistically significant, the values of average variance extracted (AVE) for every construct exceed 0.5 , composite reliability $(\mathrm{CR})$ values exceed 0.6 [57].

The results confirmed the convergent validity of all scales. In the best fitting model factor loadings for anxiety 
Table 4. Internal consistency, descriptive statistics and correlations between scales of the Warr's job-related affective well-being measure [9] in a sample of Polish employees

\begin{tabular}{|c|c|c|c|c|c|c|c|c|}
\hline \multirow{2}{*}{$\begin{array}{c}\text { Study wave } \\
\text { and job-related affect }\end{array}$} & \multirow{2}{*}{$\alpha$} & \multirow{2}{*}{ M } & \multirow{2}{*}{$\mathrm{SD}$} & \multirow{2}{*}{ SKE } & \multirow{2}{*}{ K } & \multicolumn{3}{|c|}{ Correlation* } \\
\hline & & & & & & 1 & 2 & 3 \\
\hline \multicolumn{9}{|l|}{ Time $1(\mathrm{~N}=380)$} \\
\hline 1. Anxiety & 0.88 & 2.71 & 0.99 & 0.55 & 0.08 & & & \\
\hline 2. Comfort & 0.87 & 3.56 & 1.00 & -0.05 & -0.30 & -0.55 & & \\
\hline 3. Depression & 0.91 & 2.01 & 1.01 & 1.21 & 1.24 & 0.64 & -0.53 & \\
\hline 4. Enthusiasm & 0.93 & 3.72 & 1.16 & -0.26 & -0.43 & -0.40 & 0.78 & -0.49 \\
\hline \multicolumn{9}{|l|}{ Time $2^{\mathrm{a}}(\mathrm{N}=255)$} \\
\hline 1. Anxiety & 0.86 & 2.58 & 0.95 & 0.53 & -0.09 & & & \\
\hline 2. Comfort & 0.88 & 3.60 & 1.02 & 0.03 & -0.43 & -0.60 & & \\
\hline 3. Depression & 0.91 & 2.01 & 0.93 & 1.07 & 0.70 & 0.64 & -0.50 & \\
\hline 4. Enthusiasm & 0.93 & 3.76 & 1.18 & -0.10 & -0.57 & -0.51 & 0.82 & -0.47 \\
\hline
\end{tabular}

${ }^{a}$ Two weeks after the first questionnaire completion (Time 1).

$\alpha$-Cronbach's $\alpha$; M - mean; SD - standard deviation; SKE - skewness; K - kurtosis.

* All correlations are statistically significant at least at the level of $\mathrm{p}<0.01$.

varied between 0.92 and 0.78 , for comfort varied between 0.9 and 0.78 , for depression varied between 0.91 and 0.82 , and for enthusiasm varied between 0.92 and 0.9 , all being statistically significant. The values of AVE ranged from 0.68 for comfort to 0.82 for enthusiasm. The values of CR ranged from 0.86 for comfort to 0.93 for enthusiasm.

To check if each scale captures distinct constructs, the square root of AVE for the scale is compared with its correlations with other scales [57]. If it is higher than correlations the discriminant validity is achieved. The square roots of AVE of the scales are 0.83 for comfort, 0.85 for anxiety, 0.87 for depression, and 0.9 for enthusiasm. They all exceed values of correlations between scales (Table 4).

\section{Criterion and predictive validity}

To test the criterion validity of the Polish version of Warr's job-related affective well-being measure, the relationships between its scales and the criterion variables, mood and turnover intention, have been evaluated (Table 5).
They have been calculated separately for each study wave (Time 1 and Time 2).

At both measurement times the values of correlation coefficients between enthusiasm and positive mood as well as between comfort and positive mood are statistically significant and positive (Table 5) whereas these 2 dimensions of affect are correlated negatively with negative mood. For anxiety and depression scales there are negative correlations with positive mood, and positive correlations with negative mood. Turnover intention is correlated positively with anxiety and depression dimensions and negatively with enthusiasm and comfort dimensions in both measurement times. All these correlation coefficients are statistically significant, and point out that criterion validity is reached for all scales.

Predictive validity has been assessed based on correlations between mood measured at Time 1 and job-related affect measured at Time 2. It has been assumed that positive mood will predict a higher level of enthusiasm and comfort and lower level of anxiety and depression, while negative mood has been hypothesized to show opposite 
Table 5. Correlations of the scales of Warr's job-related affective well-being measure [9] with turnover intention and positive and negative mood in a sample of Polish employees

\begin{tabular}{lcccccc}
\hline & \multicolumn{5}{c}{ Correlation* $^{*}$ measured at Time 1 } \\
\cline { 2 - 6 } Job-related affect & \multicolumn{3}{c}{$\begin{array}{c}\text { measured at Time 2 } \\
(\mathrm{N}=255)\end{array}$} \\
\cline { 2 - 7 } & $\begin{array}{c}\text { turnover } \\
\text { intention }\end{array}$ & positive mood & negative mood & $\begin{array}{c}\text { turnover } \\
\text { intention }\end{array}$ & positive mood & negative mood \\
\hline Anxiety & 0.21 & -0.36 & 0.30 & 0.26 & -0.50 & 0.44 \\
Comfort & -0.45 & 0.41 & -0.35 & -0.41 & 0.53 & -0.46 \\
Depression & 0.35 & -0.38 & 0.45 & 0.36 & -0.51 & 0.54 \\
Enthusiasm & -0.44 & 0.38 & -0.30 & -0.41 & 0.52 & -0.44 \\
\hline
\end{tabular}

* All correlations are statistically significant at least at the level of $p<0.01$.

a Two weeks after the first questionnaire completion (Time 1).

effects [40]. Obtained correlations between positive mood and enthusiasm (0.4) and comfort (0.39) measured after 2 weeks are positive whereas those between positive mood and anxiety $(-0.28)$ and depression $(-0.43)$ are negative. As expected, correlations between negative mood and comfort $(-0.36)$ and enthusiasm $(-0.38)$ after 2 weeks are negative whereas those between negative mood and anxiety (0.26) and depression (0.44) are positive. All correlations are statistically significant at least at the level of $\mathrm{p}<0.01$ and they confirm predictive validity of all scales of the measure.

Job-related affect measured at Time 1 and turnover intention measured at Time 2 is a second relationship used for assessing predictive validity of the scales. It has been hypothesized that enthusiasm and comfort will be associated with a reduced level of turnover intention, while anxiety and depression will boost it $[20,45]$. The results show that there are indeed negative correlations between comfort $(-0.43)$ and enthusiasm $(-0.4)$ with turnover intention after 2 weeks as well as positive correlations between anxiety $(0.22)$ and depression $(0.37)$ with turnover intention at Time 2. A multiple regression analysis attesting these relationships further has not been conducted because of relatively high correlations between job-related affect scales.
Summing up, the results have confirmed all hypothesis concerning relationships between job-related affect and mood as well as turnover intentions. This reveals that the Polish version of the Warr [9] measure demonstrates criterion and predictive validity capturing 4 affective dimensions in accordance with underlying theory.

\section{DISCUSSION}

The aim of the current study was to test the factorial structure of job-related affect in a Polish sample and to present the Polish adaptation of Warr's [9] job-related affective well-being measure. Firstly, we checked psychometric properties of each item of the measure. Next, we compared the goodness of fit of 6 alternative factorial models and chose the best fitting one for further analyses of reliability and validity of the measure.

Examination of alternative models confirm that Warr's [9] job-related affective well-being measure captures 4 dimensions measuring enthusiasm, comfort, anxiety, and depression as affective states different in valence and in activation level (Figure 1). Moreover, there are also other studies that confirm the 4-factor model as the best fitting to the data in samples from Poland, Spain and the Netherlands [58]. Therefore, the 
factorial structure of the Polish version of the measure is firmly established.

Moreover, the results of this study reveal that 4 scales of the Polish adaptation of the instrument achieve acceptable levels of reliability and validity. Values of Cronbach's $\alpha$ indicate good to excellent reliability of scales. Test-retest correlations indicate acceptable levels of temporal stability over a 2 week period [7]. This shows that affect at work is relatively stable, which may be treated as a bit unexpected result, but it is consistent with the results of other studies [59]. Correlations between scales of job-related affective wellbeing measure and turnover intention as well as mood show a pattern of results in line with theoretical expectations [20,40,44,45]. Higher levels of enthusiasm and comfort and lower levels of anxiety and depression may be predicted by positive mood. Conversely, negative mood fosters the growth of enthusiasm and comfort and the decrease of anxiety and depression. In addition, enthusiasm and comfort lower turnover intention and anxiety and depression boosts it in the future.

\section{Limitations and future directions}

All in all our study shows that the Polish adaptation of the job-related affective well-being measure has resulted in a psychometrically valid tool. Additional research, however, is welcome to confirm discriminant validity of the scales. For instance, relations between the job-related affect scales and other scales assessing affect at work (e.g., JAWS) [5] may be analyzed in future studies. There are results confirming partial metric measurement invariance of the scales across samples of employees from $3 \mathrm{Eu}-$ ropean countries (including Poland) and full scalar invariance across gender [58]. It is open, however, for further studies to attest measurement invariance of the instrument across other samples, for example across age groups.

This study has attested to the psychometric properties of the well-known 12-item Warr [9] measure, which has many national adaptations $[4,7,8]$. There is, however, also another 16-item instrument published recently by Warr et al. [60]. This is an extended measure of job-related affect that awaits further research and national adaptations which confirm its validity.

\section{CONCLUSIONS}

To sum up, Warr's [9] job-related affective well-being measure is an appropriate tool for measuring affect experienced at work as a multi-dimensional phenomenon. Contrary to other popular scales which capture context-free positive and negative affect (e.g., PANAS), this measure allows researchers to assess 4 dimensions of affect in a work context. This instrument may be useful for future studies in samples of Polishspeaking employees of various professions, including self-employed, as this has been validated in other studies [17,58]. Availability of the Polish adaptation of this measure may contribute to further development of research on affect in a work context, which is a dynamically growing area of investigation [2-4].

\section{REFERENCES}

1. Briner RB. The neglect and importance of emotion at work. Eur J Work Organ Psychol. 1999;8(3):323-46, https://doi.org/ 10.1080/135943299398212.

2. Bechara A, Tranel D, Damasio AR. Poor judgment in spite of high intellect: Neurological evidence for emotional intelligence. In: Bar-On R, Parker JDA, editors. The handbook of emotional intelligence. The Theory and Practice of Development, Evaluation, Education, and Application - at Home, School, and in the Workplace. San Francisco: Jossey-Bass; 2000. p. 192-214.

3. Spector PE, Goh A. The role of emotions in the occupational stress process. In: Perrewé PL, Ganster DC, editors. Exploring Theoretical Mechanisms and Perspectives. Amsterdam; New York: JAI; 2001. p. 195-232, https://doi.org/10.1016/S1479-35 55(01)01013-7. 
4. Salanova M, Llorens S, Schaufeli WB. "Yes, I can, I feel good, and I just do it!" On gain cycles and spirals of efficacy beliefs, affect, and engagement. Appl Psychol. 2011;60(2): 255-85, http://doi.org/10.1111/j.1464-0597.2010.00435.x.

5. Van Katwyk PT, Fox S, Spector PE, Kelloway EK. Using the Job-Related Affective Well-Being Scale (JAWS) to investigate affective responses to work stressors. J Occup Health Psychol. 2000;5(2):219-30, http://doi.org/10.1037/1076-8998.5.2.219.

6. Watson D, Clark LA, Tellegen A. Development and validation of brief measures of positive and negative affect: The PANAS Scales. J Pers Soc Psychol. 1988;54(6):1063-70, https://doi.org/10.1037/0022-3514.54.6.1063.

7. Mäkikangas A, Feldt T, Kinnunen U. Warr's scale of jobrelated affective well-being: A longitudinal examination of its structure and relationships with work characteristics. Work Stress 2007;21(3):197-219, https://doi.org/ 10.1080/02678370701662151.

8. Van Horn JE, Taris TW, Schaufeli WB, Schreurs PJG. The structure of occupational well-being: A study among Dutch teachers. J Occup Organ Psychol. 2004;77(3):365-75, http:// doi.org/10.1348/0963179041752718.

9. Warr P. The measurement of well-being and other aspects of mental health. J Occup Psychol. 1990;63(3):193-210, http:// doi.org/10.1111/j.2044-8325.1990.tb00521.x.

10. Merriam-Webster.com [Internet]. 2016 [cited 2016 Sep 27]. Available from: http://www.merriam-webster.com.

11. Oatley K, Keltner D, Jenkins JM. Understanding emotions. 2nd ed. Malden: Blackwell Publishing; 2006.

12. Fredrickson BL. The role of positive emotions in positive psychology: The broaden-and-build theory of positive emotions. Am Psychol. 2001;56(3):218-26, https://doi.org/ 10.1037/0003-066X.56.3.218.

13. Staw BM, Sutton RI, Pelled LH. Employee positive emotion and favorable outcomes at the workplace. Organ Sci. 1994;5(1):51-71, https://doi.org/10.1287/orsc.5.1.51.

14. Galanakis M, Galanopoulou F, Stalikas A. Do positive emotions help us cope with occupational stress? Eur J Psychol. 2011;7(2):221-40, https://doi.org/10.5964/ejop.v7i2.127.
15. Fredrickson BL. Why positive emotions matter in organizations: Lessons from the broaden-and-build model. PsycholManag J. 2000;4(2):131-42, http://doi.org/10.1037/h0095887.

16. Brief AP, Weiss HM. Organizational behavior: Affect in the workplace. Annu Rev Psychol. 2002;53(1):279-307, https://doi.org/10.1146/annurev.psych.53.100901.135156.

17. Laguna M, Razmus W, Żaliński A. Dynamic relationships between personal resources and work engagement in entrepreneurs. J Occup Organ Psychol. 2017;90(2):248-69, http:// doi.org/10.1111/joop.12170.

18. Bedyńska S, Żołnierczyk-Zreda D. Stereotype threat as a determinant of burnout or work engagement. Mediating role of positive and negative emotions. Int J Occup Saf Ergon. 2015;21(1):1-8, http://doi.org/10.1080/10803548.2015.1017939.

19. Sears K, Humiston GS. The role of emotion in workplace incivility. J Manag Psychol. 2015;30(4):390-405, https://doi. org/10.1108/JMP-11-2012-0373.

20. Baka $\ell$. How do negative emotions regulate the effects of workplace aggression on counterproductive work behaviours? Pol Psychol Bull. 2015;46(3):326-35, https://doi.org/ 10.1515/ppb-2015-0040.

21. Laguna M, Alessandri G, Caprara GV. Personal goal realization in entrepreneurs: A multilevel analysis of the role of affect and positive orientation. Appl Psychol Int Rev. 2016;65(3):587-604, http://doi.org/10.1111/apps.12061.

22. Diener E, Larsen RJ, Levine S, Emmons RA. Intensity and frequency: Dimensions underlying positive and negative affect. J Pers Soc Psychol. 1985;48(5):1253-65, https://doi. org/10.1037/0022-3514.48.5.1253.

23. Bradburn NM. The structure of psychological well-being [book review]. Psychol Med. 1976;6(01):161, https://doi.org/ 10.1017/S0033291700007637.

24. Warr P, Barter J, Brownbridge G. On the independence of positive and negative affect. J Pers Soc Psychol. 1983; 44(3):644-51, https://doi.org/10.1037/0022-3514.44.3.644.

25. Argyle M, Martin M. The psychological causes of happiness. In: Strack F, Argyle M, Schwarz N, Strack F, Argyle M, Schwarz N, editors. Subjective well-being. An inter- 
disciplinary perspective. Elmsford (NY): Pergamon Press; 1991. p. 77-100.

26. Davidson RJ. The neuropsychology of emotion and affective style. In: Lewis M, Haviland JM, editors. Handbook of emotions. New York: Guilford Press; 1993. p. 143-54.

27. Russell JA. A circumplex model of affect. J Pers Soc Psychol. 1980;39(6):1161-78, http://doi.org/10.1037/h0077714.

28. Russell JA, Carroll JM. On the bipolarity of positive and negative affect. Psychol Bull. 1999;125(1):3-30, https:/doi. org/10.1037/0033-2909.125.1.3.

29. Posner J, Russell JA, Peterson BS. The circumplex model of affect: An integrative approach to affective neuroscience, cognitive development, and psychopathology. Dev Psychopathol. 2005;17(3):715-34, https://doi.org/10.1017/ S0954579405050340.

30. Matthews G, Jones DM, Chamberlain AG. Refining the measurement of mood: The UWIST Mood Adjective Checklist. Br J Psychol. 1990;81(1):17, https://doi.org/ 10.1111/j.2044-8295.1990.tb02343.x.

31. Basińska B, Gruszczyńska E, Schaufeli W. Psychometric properties of the Polish version of the Job-related Affective Well-being Scale. Int J Occup Med Environ Health. 2014; 27(6):993-1004, http://doi.org/10.2478/s13382-014-0329-x.

32. Basińska B. [Emotions in the workplace among the professions with increased psychosocial risks]. Pol Forum Psychol. 2013;18(1):81-92. Polish.

33. Daniels K, Brough P, Guppy A, Peters-Bean KM, Weatherstone L. A note on a modification to Warr's measures of affective well-being at work. J Occup Organ Psychol. 1997;70(2):129-38, https://doi.org/10.1111/j.2044-8325.1997. tb00638.x.

34. Watson D, Tellegen A. Toward a consensual structure of mood. Psychol Bull. 1985;98(2):219-35, https://doi. org/10.1037/0033-2909.98.2.219.

35. Cifre E, Salanova M. Multidimensionality and bipolarity of a Spanish version of Warr's (1990) Well-Being Measures. J Psychol. 2002;136(1):69, https://doi.org/ 10.1080/00223980209604139.
36. Sevastos P, Smith L, Cordery JL. Evidence on the reliability and construct validity of Warr's (1990) well-being and mental health measures. J Occup Organ Psychol. 1992;65(1): 33-49, http://doi.org/10.1111/j.2044-8325.1992.tb00482.x

37. Gonçalves SP, Neves J. Factorial validation of Warr's (1990) well-being measure: A sample study on police officers. Psychology. 2011;2(7):706-12, https://doi.org/10.4236/ psych.2011.27108.

38. Dos Santos JV, Gonçalves G. [Contribution to the Portuguese adaptation of well-being at work scale from Warr (1990)]. Psicol Educ Cult. 2010 Dec;14(2):287-300. Portuguese.

39. Warr P. Age and occupational well-being. Psychol Aging. 1992;7(1):37-45, https://doi.org/10.1037/0882-7974.7.1.37.

40. Rothbard NP, Wilk SL. Waking up on the right or wrong side of the bed: Start-of-workday mood, work events, employee affect, and performance. Acad Manage J. 2011;54(5):95980, http://doi.org/10.5465/amj.2007.0056.

41. Gärling T, Gamble A, Fors F, Hjerm M. Emotional wellbeing related to time pressure, impediment to goal progress, and stress-related symptoms. J Happiness Stud. 2015;17(5): 1789-99, https://doi.org/10.1007/s10902-015-9670-4.

42. Weiss HM, Cropanzano R. Affective events theory: A theoretical discussion of the structure, causes and consequences of affective experiences at work. Res Organ Behav. 1996;18:1-74.

43. Miner AG, Glomb TM, Hulin C. Experience sampling mood and its correlates at work. J Occup Organ Psychol. 2005;78(2):171-93, http://doi.org/10.1348/096317905X40105.

44. Ilies R, Judge TA. Understanding the dynamic relationships among personality, mood, and job satisfaction: A field experience sampling study. Organ Behav Hum Decis Process. 2002;89(2):1119-39, https://doi.org/10.1016/S0749-59 78(02)00018-3.

45. Bouckenooghe D, Raja U, Butt AN. Combined effects of positive and negative affectivity and job satisfaction on job performance and turnover intentions. J Psychol. 2013;147(2):105-23, https://doi.org/10.1080/00223980.2012. 678411. 
46. Mobley WH, Griffeth RW, Hand HH, Meglino BM. Review and conceptual analysis of the employee turnover process. Psychol Bull. 1979;86(3):493-522, https://doi.org/ 10.1037/0033-2909.86.3.493.

47. Michaels CE, Spector PE. "Causes of employee turnover: A test of the Mobley, Griffeth, Hand, and Meglino Model": Correction to Michaels and Spector. J Appl Psychol. 1983; 68(4):583, http://doi.org/10.1037/h0077981.

48. Chiu RK, Francesco AM. Dispositional traits and turnover intention. Int J Manpow. 2003;24(3):284-98, https://doi.org/ 10.1108/01437720310479741.

49. Wojciszke B, Baryła W. [Scales for the measurement of mood and six emotions]. Czas Psychol. 2005;11:31-47. Polish.

50. Yin-Fah BC, Foon YS, Chee-Leong L, Osman S. An Exploratory Study on Turnover Intention among Private Sector Employees. Int J Bus Manag. 2010;5(8):57-64, https:// doi.org/10.5539/ijbm.v5n8p57.

51. Arbuckle J. Amos 6.0 User's Guide. Spring House (PA): Amos Development Corporation; 2005.

52. Kline RB. Principles and practice of structural equation modeling. New York, London: Guilford Press; 2005.

53. Browne MW, Cudeck R. Alternative ways of assessing model fit. Sociol Methods Res. 1992;21(2):230-58, https://doi. org/10.1177/0049124192021002005.

54. $\mathrm{Hu} \mathrm{L}$, Bentler PM. Cutoff criteria for fit indexes in covariance structure analysis: Conventional criteria versus new alternatives. Struct Equ Modeling. 1999;6(1):1-55, http:// doi.org/10.1080/10705519909540118.

55. Brown TA. Confirmatory factor analysis for applied research. New York: Guilford Press; 2006.

56. Cheung GW, Rensvold RB. Evaluating goodness-of-fit indexes for testing measurement invariance. Struct Equ Modeling. 2002;9(2):233-55, https://doi.org/10.1207/S15328 007SEM0902 5.

57. Hair J, Black WC, Babin BJ, Anderson RE. Multivariate data analysis. 7th ed. Upper Saddle River (NJ): Prentice Hall; 2009.

58. Łaguna M, Mielniczuk E, Razmus W, Moriano JA, Gorgievski M. Cross-cultural and gender invariance of the Warr (1990) job-related well-being measure. J Occup Organ Psychol. 2017;90(1):117-25, https://doi.org/10.1111/ joop.12166.

59. Mäkikangas A, Kinnunen U, Feldt T, Schaufeli W. The longitudinal development of employee well-being: A systematic review. Work Stress. 2016;30(1):46-70, http://doi.org/10. 1080/02678373.2015.1126870.

60. Warr P, Bindl UK, Parker SK, Inceoglu I. Four-quadrant investigation of job-related affects and behaviours. Eur J Work Organ Psychol. 2014;23(3):342-63, https://doi.org/ 10.1080/1359432X.2012.744449.

This work is available in Open Access model and licensed under a Creative Commons Attribution-NonCommercial 3.0 Poland License - http://creativecommons.org/ licenses/by-nc/3.0/pl/deed.en. 